\section{Vascular Corrosion Casting Can Provide Quantitative as Well as Morphological Information on the Microvasculature of Organs and Tissues}

Fred E. Hossler, J.H. Quillen College of Medicine, East Tennessee State University

Introduction. Complete casts of the vasculature of organs and tissues are obtained by infusing low viscosity resins into the vasculature and allowing the resin to polymerize. Dissolving away the surrounding tissue with alkali leaves a model of the intricate, three-dimensional distribution of vessels in that tissue, which is not easily obtainable by any other means, and which can then be studied with scanning electron microscopy (SEM). Because well prepared casts appear to faithfully replicate the true vascular anatomy of organs including the dimensions of vessels and details of imprints of the endothelial cells lining their lumens, they must also contain quantitative information about that vasculature 1 .

Methods $^{2}$. The species of interest is anesthetized (60 mg pentobarbital $/ \mathrm{kg}$ body weight; i.p.) and anticoagulated (700 U heparin $/ \mathrm{kg} ;$ i.p.) 30 minutes before use. The abdominal cavity is opened and the aorta (or an artery supplying the organ of interest) is cannulated and the blood is flushed from the organ with saline or Ringer solution $(370 \mathrm{C}$, at $80-100 \mathrm{~mm} \mathrm{Hg})$. Resin (Mercox/catalyst, 10/0.3; or Mercox/methyl-methacrylate/catalyst, 8/2/0.4; Ladd Research Industries, Burlington, VT) is infused through the same cannula until the onset of polymerization (usually 10 minutes). The resin-filled tissue is immersed in hot water $\left(50^{\circ} \mathrm{C}\right)$ for one hour to complete resin curing. Tissue is removed by maceration in alternating rinses of $5 \% \mathrm{KOH}$ and hot water, the resulting casts are cleaned in $5 \%$ formic acid ( 15 minutes) and distilled water, dried by lyophilization, and mounted on stubs for routine SEM. Casts are sputter-coated with gold and viewed at $10 \mathrm{kV}$ in the SEM. For vascular volume determination, resin filled tissues are weighed before and after maceration, and vascular volumes are calculated from tissue and resin densities. Vessel measurements and counts are made from micrographs. Fixation of the tissue with dilute aldehyde fixatives prior to casting enhances preservation of details of the endothelial cells as imprints on the casts, but may prolong the maceration process.

Results and Discussion. High quality casts display the 3-dimensional arrangement of the vasculature of organs (Figures $1,2,3$ ) including arteries, capillaries, and veins and their valves, and may exhibit details of the endothelium on the cast surfaces, including imprints of endothelial nuclei (Figures $3,4,5$ ) and endothelial cell borders. From these imprints one can observe the orientation of the endothelial cells with regard to the vessel axis, determine the number of endothelial cells per unit area, and from this calculate an average lumenal surface area for the endothelial cells. In arteries, endothelial cells are usually very much elongated, lying parallel with the long axis of the vessel (Figures 3,4 ), in contrast to those in veins and capillaries which

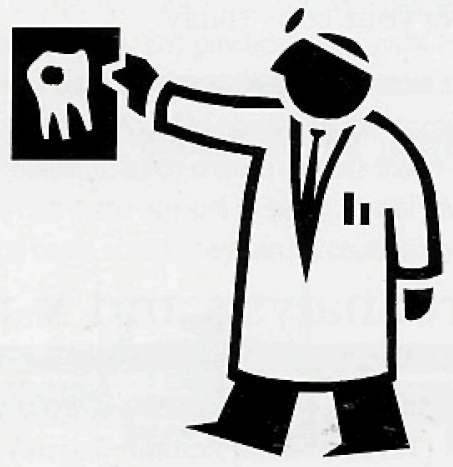

are more rounded and less highly oriented (Figure 5). For example, in the cast of an arterial surface from a duckling eye shown in Figure 4, there are on the average 3.03 endothelial cells per $1000 \mu \mathrm{m}^{2}$ and, therefore, each cell covers an area of about $328 \mu \mathrm{m}^{2}$ of the vessel wall. In this case nuclear imprints average $16 \mu \mathrm{m}$ in length, whereas in the cast of the choriocapillaris of the ducking eye shown in Figure 5 , they are more rounded and average $13 \mu \mathrm{m}$ in length.

If one is reasonably certain that all vessels in a tissue have been filled with resin (and it is often difficult to make this assumption with real assurance), vascular volume estimates can be made from tissue and cast weights and densities 2.3. Resin density was determined to be $1.28 \mathrm{~g} / \mathrm{mL}$ from polymerized resin blocks and a reported value of $1.05 \mathrm{~g} / \mathrm{Ml}$ was used for tissue density. Table I shows some example measurements made from corrosion casts from rat heart and hamster lung under several different conditions. It is worth noting that the values for capillary diameter and intercapillary distance measured from casts of rat heart very closely match those determined in vivo.

Summary and Potential Other Application of Corrosion Casting. Many other examples of the use of vascular corrosion casting for obtaining quantitative information are found in the literature, but for simplicity this report is limited to our own work. While the primary application of vascular corrosion casting has been, and likely will remain, in the elucidation of the 3-dimensional distribution of vessels in tissue and organs, high quality casts also yield valuable quantitative information about that vasculature. In addition, I see no obvious reason why the corrosion casting method could not be used to describe or measure the internal volume of any hollow or porous structure or material as long as methods are available to remove the surrounding material and leave the cast intact. Applications might include determinating the core of a mold, or the shape or volume, to the lumen of a tube, or demonstrating the distribution of interconnected spaces within penetrable substances in material science. Similarly, the volumes of hollow organs such as the urinary bladder or ureter could also be measured. Incorporation of marker substances in the casting resin (e.g., isotopes, heavy metals, electron dense materials, photo-sensitive materials, or fluorescent substances) to enhance quantitative measurements are also being considered in some laboratories.

\section{Table I: Example Measurements From Corrosion Casts}

\begin{tabular}{|c|c|c|}
\hline Parameter & Hamster lung ${ }^{\star}$ & Adult Rat Heart* Geriatic Rat Heart* \\
\hline (inflated) & $\begin{array}{l}\text { (3-5 mo old, } \mathrm{r} \\
\text { ventricular free } \mathrm{v}\end{array}$ & $\begin{array}{l}\text { ight } \quad(19-20 \text { mo old, right } \\
\text { wall) } \text { ventricular free wall) }\end{array}$ \\
\hline
\end{tabular}

\begin{tabular}{lccl}
\hline Capillary diameter & - & $5.6 \pm 1.9 \mu \mathrm{m}$ & $5.7 \pm 2.3 \mu \mathrm{m}$ \\
Intercapillary distance & - & $14.9 \pm 4.9 \mu \mathrm{m}$ & $12.7 \pm 5.6 \mu \mathrm{m}$ \\
Capillary density & - & - & $22.2 / 10^{4} \mu \mathrm{m}^{2}{ }^{\star *}$ \\
Vascular volume & $11.33 \pm 1.17 \%$ & $10.01 \pm 1.06 \%$ & $9.10 \pm 1.67 \%$
\end{tabular}

*values are means $\pm s d 2,3$

* mean from 17 samples

\section{Literature Cited}

1. Kratky, R.G., Zeindler, C.M., Lo, D.K.C., and Roach, M.R. 1989 Quantitative measurements from vascular casts. Scanning Microscopy 3:937-943.

2. Hossler, F.E., Douglas, J.E., and Douglas, L.E. 1986 Anatomy and morphometry of myocardial capillaries studied with vascular corrosion casting and scanning electron microscopy: a method for rat heart. Scanning Electron Microscopy/1986/V: 1469-1475.

3. Hossler, F.E., Douglas, J.E., Verghese, A., and Neal, L. 1991 Microvascular architecture of the elastase emphysemic hamster lung. J. Electron Microscopy Tech. 19:406-418. 

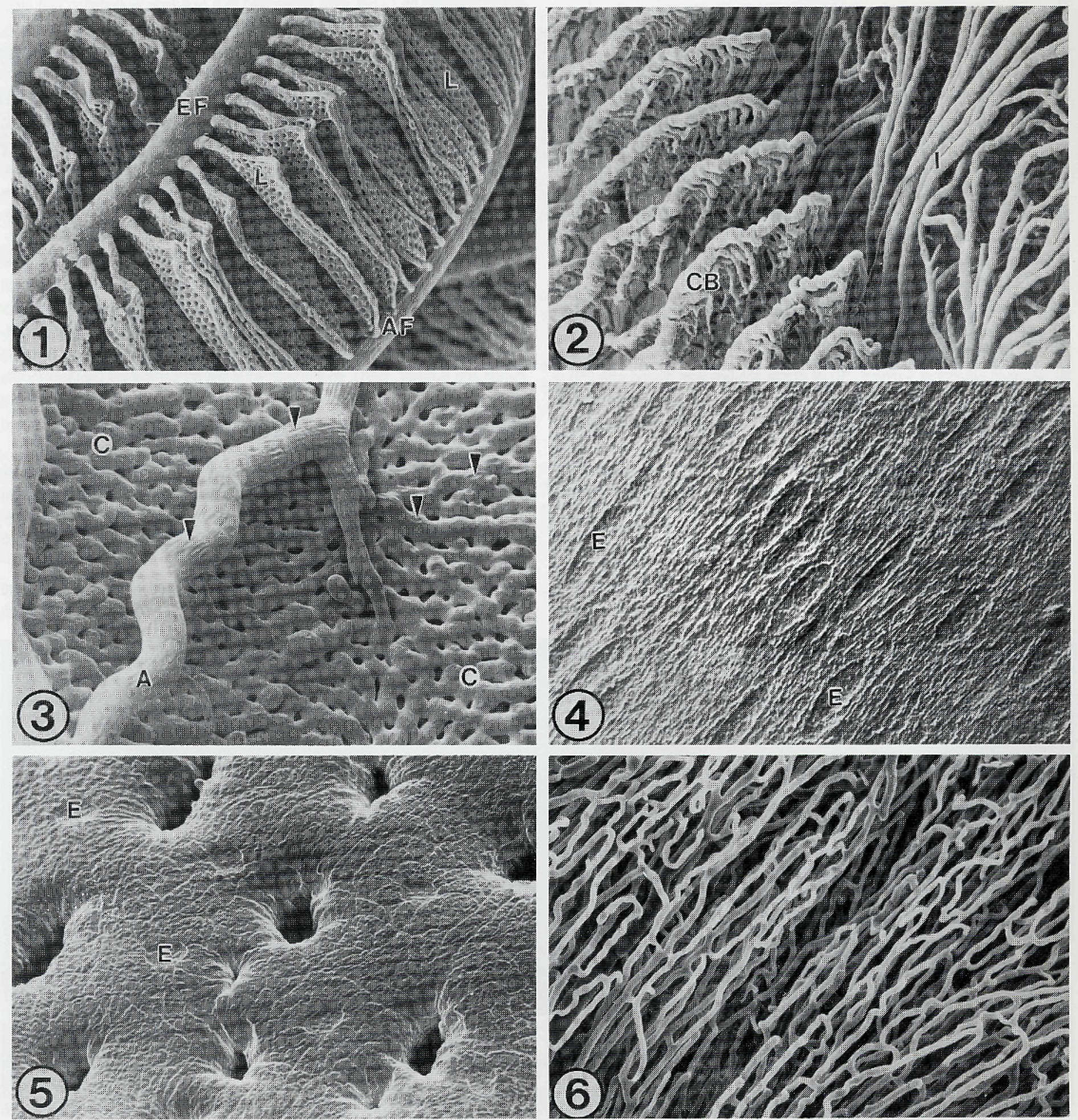

Figure 1. Vascular corrosion cast of a portion of a hybrid striped bass/white bass gill. $A F$, afferent filamental artery; $E F$, efferent filamental artery; $L$, capillary beds of secondary lamellae. $\times 154$

Figure 2. Vascular corrosion cast of a portion of a ducking eye showing capillary beds of ciliary bodies (CB) and the posterior iris (I). $\mathrm{x} 98$

Figure 3. Vascular corrosion cast of a portion of a bull frog eye showing an artery (A) supplying the choriocapillaris (C). Arrowheads, endothelial imprints. $x 113$

Figure 4. Surface of a corrosion cast of an artery in the ducking eye showing endothelial imprints $(E) . \times 1145$

Figure 5. Vascular corrosion cast of a portion of the choriocapillaris of the ducking eye. $E_{1}$ endothelial imprints. $x 559$

Figure 6. Vascular corrosion cast of a portion of the endocardial surface of a ventricle from an adult rat heart showing capillary beds of the trabecular muscles. $\times 247$ 